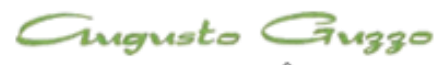

REVISTA ACADEMICA

\title{
O Papel da Nova Classe Média na Economia Brasileira
}

\author{
José Flavio Messias ${ }^{1}$ \\ Recebido em: 16/12/2013. Aprovado em: 22/12/2013. Disponibilizado em: 22/12/2013 \\ 1. Bacharel e Mestre em Economia, Doutor em Relações Internacionais PUC/SP, professor economia e gestão financeira em \\ diversas IES.
}

\section{Resumo}

Este artigo tem como objetivo realizar uma breve discussão sobre os diferentes conceitos a aplicações a respeito da chamada nova classe média ou nova classe trabalhadora. Tal definição desta parcela da sociedade brasileira é de suma importância, pois reflete nos rumos da economia no que tange a adoção de políticas públicas que tenham como premissa o desenvolvimento econômico nacional. Através de diferentes abordagens dos estudiosos sobre o tema, a nova classe média ou nova classe trabalhadora é revisitada e ganha diferentes enfoques a partir do momento em que se depara com a histórica dificuldade de conceituar-se de maneira satisfatória a classe média, ou nova classe trabalhadora, levando em consideração as particularidades de cada conceito e sua respectiva aplicação. A pesquisa bibliográfica traz importantes considerações a respeito deste estrato da sociedade do Brasil atual, com o cenário econômico relativamente estável, em comparação com a crise econômica encontrada em diversas nações europeias.

Palavras-chave: Classe média; classe trabalhadora; política crédito; crescimento econômico.

\begin{abstract}
This research focus on quickly verify, besides highlighting, the different concepts regarding what it should be labeled as the new middle class or the new working class. Such definition of this part of Brazilian society is of great importance because it reflects the direction of the economy towards the adoption of public policies that are premised on national economic development. Through different scholars' approaches on the subject, the new middle class or working class is revisited and acquires different approaches from the moment it faces the bistorical difficulty of satisfactorily conceptualizing the middle class or new working class, taking into account the particularities of each concept and its implementation. The literature offers important considerations regarding this stratum of society in Brazil today, with the economic scenario relatively stable compared to the economic crisis found in several European nations.
\end{abstract}

Keywords: Medium class; Working class; credit police; Economic growth. 


\section{Introdução}

A ascensão social da chamada nova classe média ou classe $\mathrm{C}$, proporcionada por diversos fatores, tais como a estabilidade econômica atual frente ao péssimo cenário econômico brasileiro encontrado na década de 80 , além dos diversos programas sociais implantados pelo poder público, nas esferas federais, estaduais e municipais também foram decisivos. Soma-se a estes fatores também, o acesso facilitado ao crédito abundante disponibilizado no mercado: os novos consumidores que por muito tempo estiveram distantes dos bancos e do crédito em geral, agora são massivamente assediados, desde as propagandas veiculadas pelos grandes bancos nos meios de comunicação, como também nas grandes lojas de varejo e também nas lojas dos bairros, sem contar as inúmeras ações de telemarketing de inúmeras empresas do ramo financeiro. As empresas em geral enxergam nesse público um nicho bastante inexplorado que pode render bons negócios.

Este artigo tem como objetivo discutir o conceito de nova classe média e seus impactos no cenário econômico atual. Convém-se afirmar a inegável melhora nos índices econômicos e sociais, alardeados em todos os cantos pelos governantes. Portanto, um melhor conhecimento desta nova classe social ou nova classe trabalhadora permite não só entender o que proporcionou a melhora de vida desta parcela da população, mas também que se tome conhecimento dos caminhos trilhados por esse estrato do povo brasileiro e também as consequências das medidas tomadas. Não falta literatura científica, revistas e jornais especializados, além da mídia em geral no retrato de diversos perfis, traçando alguns parâmetros e opiniões a respeito da nova classe média ou nova classe trabalhadora. Entretanto, dada a riqueza proporcionada pela discussão deste assunto, se faz amplamente necessário conhecer melhor os fatores que favoreceram $O$ surgimento desta situação, além daqueles que compõem esta parcela da população para que se possa afirmar se de fato temos uma nova classe média ou apenas uma nova configuração da classe trabalhadora.

\section{Fundamentação Teórica}

Diferentes abordagens sobre a conceituação da classe média através do olhar sociológico e econômico enriquecem $\mathrm{O}$ debate ideológico que permeiam o meio acadêmico e que, teoricamente, serve como base para a adoção de políticas públicas que favoreçam o progresso de nosso país. Portanto, o presente artigo pretende fazer uma breve leitura dos conceitos a respeito da nova classe média ou nova classe trabalhadora.

Wright Mills (1976) ao discorrer sobre a formação da classe média americana caracterizada pelos colarinhos brancos e sua representação perante a sociedade, afirma que tal classe é fruto de criação da comunicação de massa, em detrimento da experiência. Ressalta ainda que tal classe era vista como digna de pena por aqueles que se encontravam acima deles, mas que era objeto de admiração das classes inferiores.

Segundo Friedman (2005) ao falar-se da classe média, deve-se ter em mente determinada parcela da sociedade que possui a pretensão de futura ascensão social, embasado principalmente na diferenciação social a partir do consumo.

Este tipo de categorização ainda é encontrada nos tempos atuais, onde a nova classe média inclui a manicure que não possui o ensino fundamental completo, o microempresário que possui graduação completa, o executivo com pós-graduação, ou seja, conforme afirmam Souza \& Lamounier (2010) a nova classe média é 
composta de parcelas da população identificáveis somente em termos estatísticos.

\section{Metodologia}

O presente trabalho constitui-se numa pesquisa exploratória, descritiva e focada na análise de conteúdo. A fase exploratória baseou-se numa pesquisa bibliográfica, identificando os principais livros, periódicos e artigos científicos produzidos relacionados ao tema, e, posteriormente, foi realizada e a análise crítica e reflexiva dos mesmos.

A fase descritiva teve o objetivo analisar Serão abordados diferentes conceitos de nova classe média, e suas implicações. Para tanto, a metodologia utilizada na construção deste artigo está pautada pela pesquisa qualitativa e revisão da bibliografia sobre os conceitos da classe média ou nova classe trabalhadora, permitindo a formalização de um constructo, a formatação de uma ideia que abarque de maneira sucinta as implicâncias desta nova classe média ou nova classe trabalhadora, fomentando com subsídios necessários para o melhor entendimento da nova classe média ou nova classe trabalhadora, que constitui o principal objetivo deste artigo.

$\mathrm{Na}$ análise de conteúdo, ela admite tanto abordagens quantitativas quanto qualitativas, presta-se tanto aos fins exploratórios quanto ao de verificação, confirmando ou não hipóteses ou suposições preestabelecidas. A análise de conteúdo é composta por três etapas: a) a análise preliminar, b) a exploração do material, c) tratamento dos dados e interpretação (Vergara, 2010).

\section{Distribuição de renda e diminuição da} pobreza

É impossível evitar a comparação da atual situação econômica relativamente estável encontrada no Brasil atual, com aquela encontrada pelas famílias brasileiras na década de 80. De acordo com Contador (1985), o índice anual de inflação atingiu três dígitos, fato inédito na história brasileira. Concomitantemente, a taxa de crescimento econômico caiu vertiginosamente, alcançando vergonhosamente valores negativos, fato também inédito no Brasil pósguerra.

Posteriormente, após uma verdadeira enxurrada de planos econômicos, algumas condições do ambiente macroeconômico colaboraram no êxito do plano real no controle inflacionário Giambiagi (2005), trazendo certa estabilidade para a economia brasileira.

Oliveira (2012) afirma que em 2005, surge um novo momento expresso pelo aumento da classe média brasileira, fomentado pela facilitação promovida na expansão do crédito, no controle inflacionário, da estabilidade e de crescimento econômico, fornecendo a sustentação na retomada da oferta de empregos formais e do movimento expansionista dos programas governamentais de redistribuição de renda, que também colaboraram com a economia brasileira.

Crises internacionais e planos econômicos à parte, o Brasil vivencia uma condição econômica que favoreceu importantes alterações nos quesitos econômicos e sociais. De acordo com a Comissão para definição da classe média no Brasil (2012) foi possível alcançar a redução da extrema pobreza à metade em apenas cinco anos, conforme abaixo: 
Gráfico 1

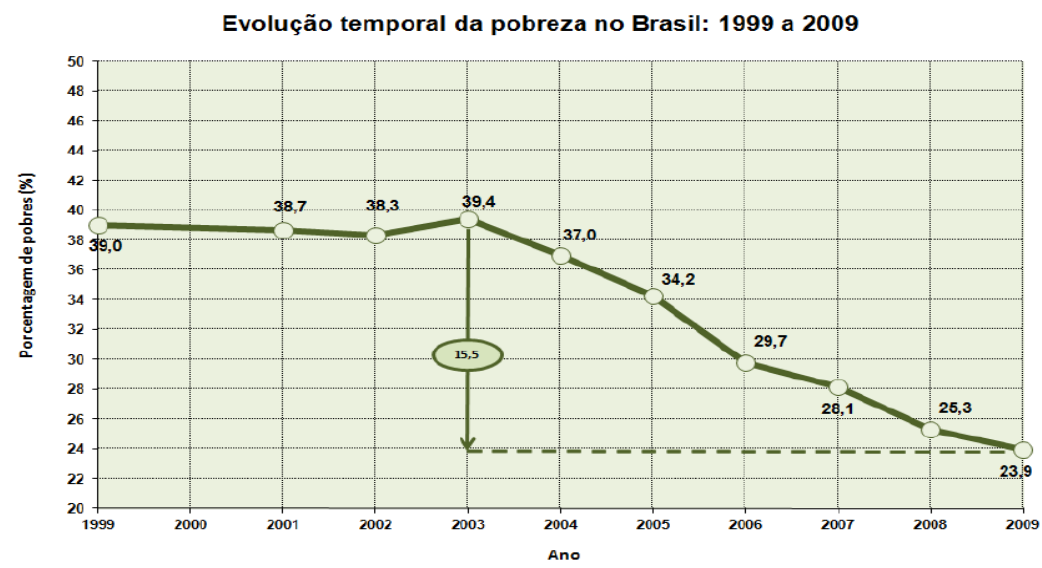

Houve significativa diferenciação nas taxas de crescimento de renda em comparação com as camadas mais pobres em relação às camadas mais ricas da população brasileira:

Enquanto a renda dos $10 \%$ mais ricos cresceu apenas a metade da média brasileira na última década, os 10\% mais pobres cresceram quase duas vezes e meia acima dessa média (Gráfico 2) Pode-se dizer que a renda dos mais ricos cresceu a taxas europeias, enquanto a renda dos mais pobres cresce a taxas chinesas. (COMISSÃO PARA DEFINIÇÃO DA CLASSE MÉDIA NO BRASIL, 2012, p. 5).

\section{Gráfico 2}

Taxa de crescimento médio da renda domiciliar per capita por décimos da distribuição: Brasil, 2001 a 2009

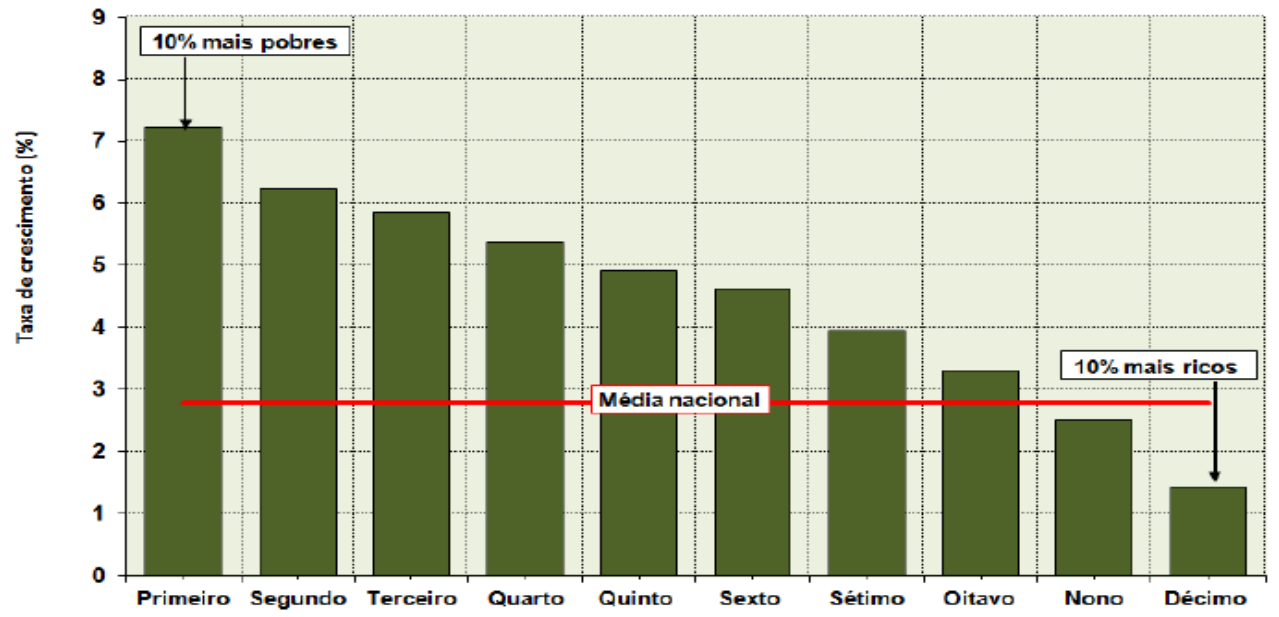

Fonte: Estimativas produzidas com base na Pesquisa Nacional por Amostra de Domicílios (PNAD) de 2001 a 2009. 
Verificou-se uma significativa diminuição da pobreza e também elevação de renda nas camadas mais pobres, representativa fatia da população alcançou a classe possuidora de renda média. Na medida em que as classes média e alta não tiveram a mesma pujança na elevação de suas rendas, é possível constatar o aumento da classe média brasileira.

\section{Conceituando a classe média}

Neri (2008) utilizou-se da definição de limites das classes sociais com base no trabalho desenvolvido por Ferreira et al (2003), iniciando pela classificação de miséria correspondendo a renda domiciliar deste grupo entre 0 e 768 reais por mês, com base na existência de 4,31 habitantes por domicílio. Neri (2008) conceitua também a definição dos outros grupos com base na pesquisa mensal de emprego no período de 2002 a 2006. A renda da classe D, localizada um degrau acima que a classe $\mathrm{E}$ (miseráveis) está localizada entre 768 e 1064 reais como renda total domiciliar mensal. $\mathrm{O}$ autor segue definindo a classe média considerando a renda domiciliar total entre 1064 e 4591 reais por mês, sendo este intervalo de classe média considerado em seus estudos.

Para Neri (2008), dentre as diversas informações a respeito das classes econômicas brasileiras, se destaca a evolução destas classes, afirmando ainda que no período compreendido entre 2003 e 2009, 23 milhões de pessoas deixaram a base da pirâmide social (classes D e E), ascendendo para as classes ABC. Neri (2010) também ressalta que $52 \%$ da população brasileira situa-se no estrato médio, sob a definição de classe média como aquela que possui emprego formal, acesso ao crédito, além de um carro ou uma motocicleta.

A classe $C$ é a classe central abaixo da A e B e acima da D e E. A fim de quantificar as faixas, calculamos a renda domiciliar per capita do trabalho e depois a expressamos em termos equivalentes de renda domiciliar total de todas as fontes. A faixa $C$ central está comprometida entre os $\mathrm{R} \$ 1.064$ e os $\mathrm{R} \$ 4.561$ a preços de hoje na Grande São Paulo. A nossa classe C está compreendida entre os imediatamente compreendidos acima dos 50\% mais pobres e os $10 \%$ mais ricos na virada do século. (Neri, 2008, p.5)

Segundo Pochmann (2012), a configuração dessa nova classe média é questionável, na medida em que os perfis e atributos pertinentes a esta nova classe na verdade não são identificados de maneira clara e precisa: declara ainda que tal visão de classe média está ligada ao fomento do consumismo, aos êxitos da globalização neoliberal e a ausência de debates a respeito da dinâmica das mudanças econômicas e sociais.

A metamorfose pela qual passa a atual estrutura social brasileira prescinde de interpretações mais profundas e abrangentes, que possam ir além da abordagem rudimentar e tendenciosa a respeito da existência de uma nova classe média. Pode-se até estranhar a inclinação de certas visões teóricas recentes, que buscam estabelecer para determinado estrato da sociedade agrupado quase exclusivamente pelo nível de rendimento e consumo - o foco das atenções sobre o movimento da estrutura social do país. (Pochmann, 2012, p.7).

Souza (2010) também discorre sobre a possibilidade de nomear esta parcela da população de nova classe média, alegando que para tal denominação ser pertinente, a prerrogativa de acesso facilitado ao capital cultural deveria ser uma constante, pois tal recurso escasso é de suma importância. Afirma ainda que a parcela da população denominada como nova classe média na verdade se trata de um grupo trabalhador, e 
que pela ausência de acesso diferenciado ao capital cultural, não pode ser classificada como nova classe média.

De acordo com Bonelli (1989), a classe média detém o construto da visão de mundo esculpida na base da diferenciação e reconhecimento social, especialmente no que diz respeito ao reconhecimento profissional alcançado. Os valores da classe média direcionam-se para a tomada de decisões que privilegiam um estilo de vida mais arrojado em comparação com aquele adotado pelas classes inferiores, que servem como modelo comparativo para a sua própria percepção de como devem agir para aproximar-se das classes mais altas e para isso, adotam uma postura mais voltada ao consumismo.

Segundo Oliveira (2012 apud POCHMANN ET AL,2006, p.88), a definição de classe média passa pelas famílias que auferem participação financeira que se encontram nos três mais altos decis da distribuição nacional de renda pessoal, sem levar em consideração a relativa participação na distribuição pessoal da renda daqueles que representam o 1\% mais rico do país. Embasados por este cálculo e com a utilização dos dados do Censo 2000, afirmam que $31,7 \%$ das famílias brasileiras encontramse na classe média.

Voltando as definições de Pochmann et al. (2006, p.88), é notável a diferença da classe média no Brasil quando se compara com a mesma classe em outros países no que tange ao valor atribuído a determinados privilégios, a saber: acesso ao consumo de serviços pessoais (empregada doméstica, motorista particular, cozinheira ,babá, segurança particular), sendo a extensão de acesso a tais serviços uma definição do estilo de vida adotado pela classe média brasileira, que fatalmente está ancorado no consumismo como diferencial.
O consumo assume um valor suplementar de relacionamento e de aparência, capaz de possibilitar identificação com elevado status social, dentro do projeto mais amplo de prosperidade fundado na ascensão e mobilidade intergeracional. (...) Com isso a classe média acaba por comprometer parcelas significativas de sua renda em gastos inversionais como roupas, habitação, diversão, educação, bem acima das despesas com "autoconservação", como seriam as de alimentação e saúde. (POCHMANN et al, 2006, p.88)

Esta cultura voltada ao consumismo da classe média contrasta com aquela adotada pelos mais pobres. Conforme afirma Oliveira (2012) após uma breve observação a respeito dos gastos daqueles mais pobres em comparação com a classe média, é possível afirmar que a parcela mais pobre tem seus gastos concentrados na manutenção da subsistência, na alimentação, habitação, vestuário e demais cuidados pessoais. A autora ainda destaca como considerável o valor gasto com cigarros. Em contrapartida, a classe média propriamente dita gasta boa parte de seu orçamento familiar com educação, lazer e cultura, nos remetendo ao conceito do capital cultural, já citado anteriormente por Souza (2010), além dos gastos com transporte, assistência médica e demais serviços pessoais.

Ainda de acordo com Oliveira (2012), a procura de manutenção de determinado padrão de vida em busca da aquisição de um status social elevado em comparação ao seu potencial efetivo de compra, faz como que a nova classe média eleve o seu endividamento, sendo que a expansão do crédito ocorrida a partir de 2004 e 2005, além do recente corte nas taxas de juros por parte do governo, caracteriza um cenário teórico de consumo e aumento da nova classe média no Brasil. 


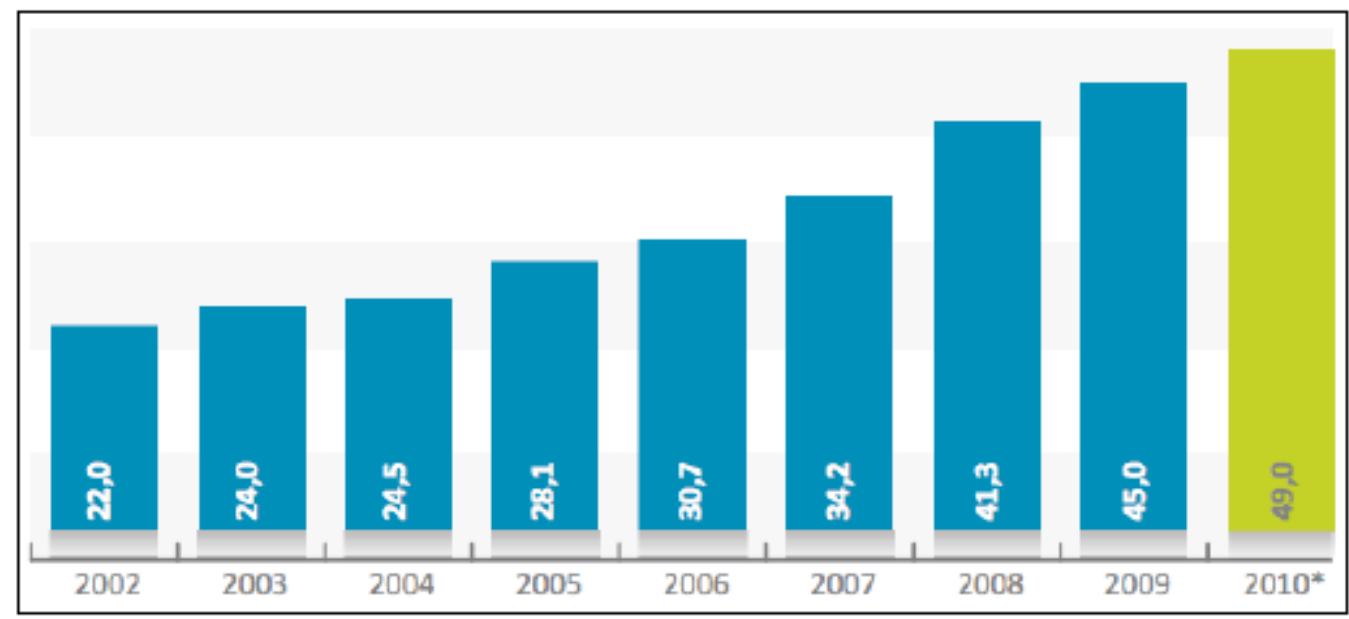

Gráfico 3 - Empréstimo do sistema financeiro (\% do PIB)

Dados em: \% do PIB (posição de dezembro de cada ano)* estimativa Ministério da Fazenda Fonte: Banco Central Elaboração: Ministério da Fazenda (BRASIL, 2010a)

A elevação do crédito no Brasil é notável. Como é possível verificar no gráfico 3, estimou-se que a expansão tenha colocado o nível de financiamento a $49 \%$ do PIB, nível próximo àquele encontrado ao padrão de outras economias, todavia, baixo e distante daquele esperado considerando o tamanho da sua economia.

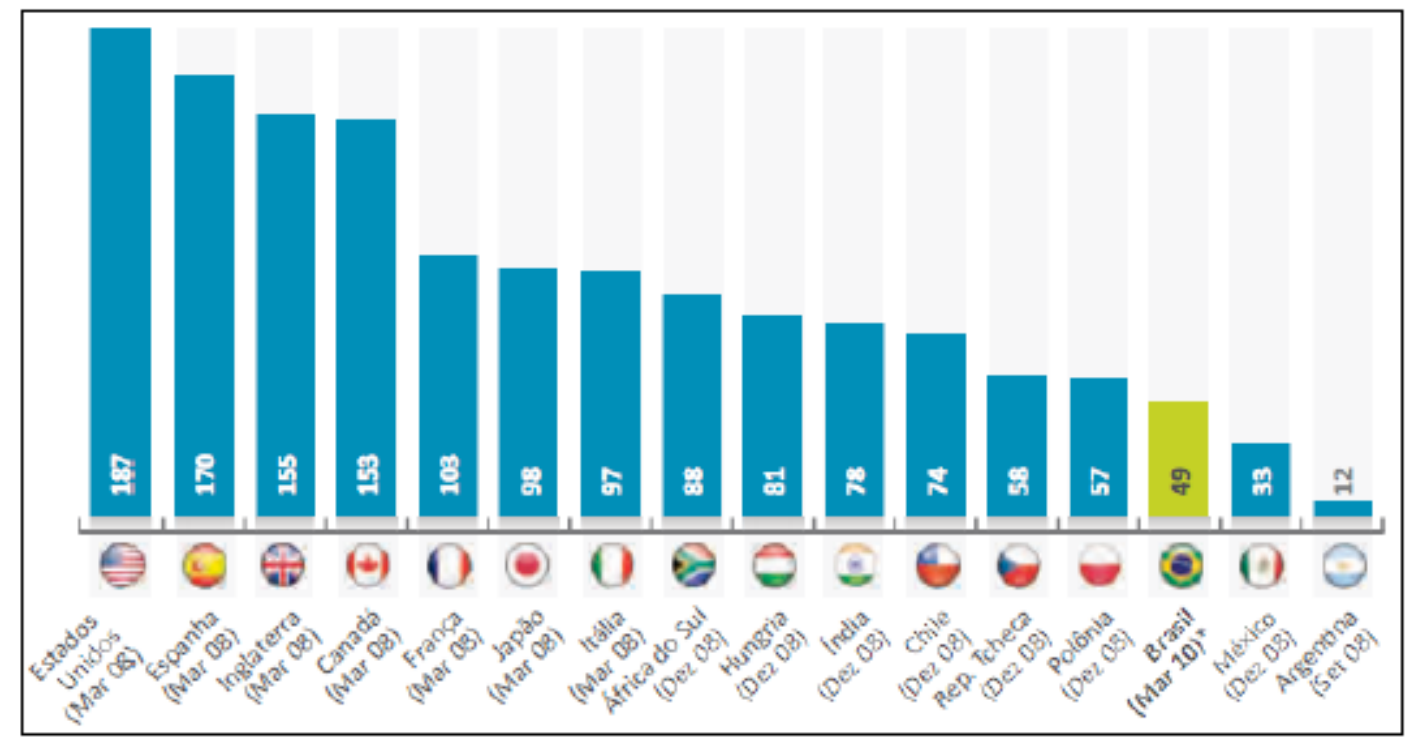

Gráfico 4 - Crédito - Países Selecionados (\% do PIB) - 2008 e 2010

Dados em: \% do PIB * Estimativas do Governo

Fonte: Ecowin e Moodys Elaboração: Ministério da Fazenda (2010)

Entretanto, este cenário positivo de consumo e da sustentabilidade deste movimento de ascensão social é questionado por Souza \& Lamounier (2010). Apesar de afirmarem que a elevação da classe média e consecutivamente o aumento do seu poder de compra colaboram com a expansão do mercado de consumo, mesmo considerando que determinados investimentos em capital humano, como por exemplo, plano de saúde, 
educação particular, poupança ou outros investimentos financeiros estarem ligados à classe média mais tradicional, a nova classe média, que tanto aspira ela ascensão social, e copia em parte os gastos em telefonia móvel, computadores e acesso rápido à internet, ainda está implicada na inconstância da renda familiar que é ocasionada por empregos que não se caracterizam como estáveis ou até mesmo pelas atividades autônomas que encontram obstáculos para prosperarem na manutenção do perfil de consumo esperado.

O caminho muitas vezes encontrado é do endividamento além do capital disponível, ocasionando elevado risco de inadimplência. Ainda conforme postulam Souza \& Lamounier (2010) a sustentabilidade deste modelo é questionável, levantando três dúvidas principais: o aumento da distribuição de renda, que ainda nos dias atuais é uma das mais desiguais no mundo, a realização de reformas estruturais, que englobem questões trabalhistas e tributárias, pilares da sustentação do aumento da formalização da economia e da competitividade e também o atual cenário que dependeu do consumo de forma categórica, ao invés do estabelecimento de padrões novos e atuais de organização ou mesmo do aumento de desempenho na produção.

Como afirma Alves (2011) é sabida a existência de diferentes vieses e questões a respeito dos métodos aplicados na conclusão do conceito de classes sociais em função da padronização no que diz respeito a renda e consumo. Todavia, o aumento do mercado interno, na comercialização de bens de consumo e serviço, se constitui como um indicador que possa ser adotado.

Souza (2010) postula no sentido de que as classes sociais não devem ser conceituadas levando em consideração a renda: sua visão de mundo deve ser notada através de seus comportamentos e atitudes que se caracterizam por sua praticidade ou como tem sido categorizada como nova classe média para os trabalhadores brasileiros.

Este conceito de nova classe média está intimamente conectado à necessidade de um viés carregado de positivismo, ou seja, construído sob a ótica da necessidade de se encobrir as dificuldades, os conflitos e contradições desta parcela do povo brasileiro, excluindo as imperfeições e malefícios do capitalismo financeiro. Com base nessas afirmações, o autor também ressalta a tentativa da construção de um quadro que vislumbre uma parte da sociedade brasileira que já trilha o caminho do primeiro mundo.

Souza (2010) define a mesma categoria de nova classe média trata-se de uma definição ufanista no esforço de camuflar contrassensos respeitáveis e recorrentes no cotidiano destes brasileiros, construindo a ideia de que o capitalismo financeiro é costumeiramente positivo e perfeito. Pretende-se divulgar o conceito de que existe uma grande parte da sociedade brasileira, do novo tipo, que caminha na direção do primeiro mundo. $\mathrm{Na}$ ambição de prover um entendimento mais qualitativo do quem vem a ser este acontecimento contemporâneo, o autor faz uso de distintas abordagens utilizadas em diversos estudos recentes relacionados a este assunto e sugere um entendimento analítico fundamentado empiricamente com pesquisas qualitativas produzidas ao longo do nosso país.

Um dos fatos mais importantes ocorridos nos últimos tempos foi $\mathrm{O}$ aparecimento desta nova classe média: esta parcela do povo brasileiro composta de milhões de pessoas que emergem das camadas mais baixas da população que arduamente batalham para criar e sustentar seus micro e pequenos negócios ou mesmo aspirar melhores colocações dentro de companhias ora estabelecidas, são brasileiros que continuam seus estudos no horário noturno, frequentam a novas igrejas e 
associações, e se apoiam culturalmente com atitudes positivas e de autoajuda. Praticamente alheia aos olhos das classes mais altas que constituem a elite do poder, culturalmente e financeiramente, a nova classe média permeia o conceito de qualidade de vida ambicionado pelo povo, sendo o lugar onde nosso povo deseja chegar (Souza, 2010).

Entretanto, Souza (2010) segue afirmando a necessidade de se conceituar a nova classe média como nova classe trabalhadora:

As classes dominantes - classe média e classe alta - se definem, antes de tudo, pelo acesso aos dois capitais impessoais (econômico e cultural) que asseguram, por sua vez, todo tipo de acesso privilegiado a literalmente todos os bens (materiais ou ideais) ou recursos escassos em uma sociedade de tipo capitalista moderna (SOUZA, 2010, p. 48).

Souza (2010) a nova classe trabalhadora não opera no que diz respeito ao estabelecimento de vicissitudes particularmente ligadas as classes alta e média. Tal classe possui características próprias: a nova classe trabalhadora é considerada comunitária e distante do individualismo no tocante as suas decisões. Também reside nos bairros onde se encontram seus parentes e amigos e principalmente esta classe não possuiu o acesso privilegiado ao capital cultural, que invariavelmente proporciona boas colocações no mercado de trabalho, característica marcante da classe média. A nova classe média galga suas posições com base no seu próprio mérito e esforço diário, com seu potencial de resiliência diferenciado, que lhe permite suportar o cansaço de várias jornadas de trabalho, muitas vezes em diferentes empregos, além da jornada de estudos, e também da força de resistir aos impulsos de consumo imediato, denotando aumento na sua capacidade de poupança, além da confiança na sua capacidade de trabalho.

Como afirmou Souza (2010) tais características marcantes são oriundas do "capital familiar" que nada mais é do que o agrupamento das interligações e disposições para estes comportamentos próprios desta classe nova, sendo o que de fato caracteriza a elevação desta classe é o repasse destes valores, do trabalho esforçado e sequenciado, mesmo que em detrimento de melhores condições de vida. Grandes parcelas destes trabalhadores têm família estruturada, com seus clássicos papéis atualizados, mesmo que usufruam de um mínimo capital econômico e com um baixo capital cultural e acadêmico.

Esta nova classe trabalhadora está moldada na transmissão da "ética do trabalho" diretamente aprendida em sua prática, quando que a classe média adquire tal conceito através da "ética do estudo". Os batalhadores que constituem a nova classe trabalhadora em grande parte não obtiveram as benefícios oriundos de anos e anos de estudo: trabalhar desde cedo e paralelamente estudar é uma das particularidades desta classe trabalhadora, quando que os jovens pertencentes à classe média se preocupam exclusivamente com seus estudos.

Souza (2010) discute também sobre as características marcantes da nova classe trabalhadora, que propiciaram a sagacidade necessária para que tal classe pudesse internalizar a possibilidade de mudança e progresso como desejo possível de alcance. Frente à precarização do trabalho formal, a nova classe trabalhadora também entende que o fato de alcançar melhor qualificação profissional não garante estabilidade no mercado de trabalho. Também não traça nenhum paralelo quanto à aquisição de conhecimentos escolares, tampouco a garantia de acesso ao ensino de nível superior.

Posto isto, Souza (2010) segue afirmando que a questão da renda não é o 
fator que evidencia a diferença entre nova classe média e a nova classe trabalhadora, sendo que a maneira de agir, pensar e sentir são as características da vida cotidiana que permitem identificar os membros pertencentes a uma classe ou a outra. Assim, o autor afirma que a nova classe trabalhadora pôde introjetar mesmo que de maneira mínima, algumas características indispensáveis ao que se convém afirmar como sobrevivência produtiva, tais como: a resiliência no âmbito do trabalho, além da prática de poupança, mesmo que de maneira inconstante.

Tais características elencadas por Souza (2010) constituem uma parcela de uma identidade de classe. Conforme afirmado por Bauman (2005) a identidade só é por nós sabida como coisa a ser inventada e não descoberta; como uma meta que necessita de esforço para ser alcançada. A identidade se apresenta como possível de construção, a começar do nada ou passível de escolha dentre alternativas. Sendo assim, a partir da aquisição de modos específicos de desenvolvimento adquiridos por um grupo de pessoas através do seu próprio sacrifício e esforço, caracterizando estes aspectos como identificáveis e de fácil reconhecimento.

Segundo Pochmann (2012) as diversas mudanças sociais, destacando-se aquelas ocorridas nos últimos oito anos, não caracterizaram fatores que culminassem na criação de uma nova classe média no país. $\mathrm{O}$ autor segue afirmando que a geração de empregos nos últimos anos colaborou para a criação de uma classe trabalhadora consumista, individualista e despolitizada, sendo que este movimento ascensionista da classe trabalhadora já demonstra sinais de esgotamento e que agora o governo deverá adotar algumas medidas que visem o aumento da geração de empregos.

Tratando-se do Brasil, muitas das vagas geradas não têm sua origem na indústria e sim nos serviços, que são consumidos pela nova classe trabalhadora. A classe média detém uma base bastante diferente dos novos segmentos brasileiros de classe. A classe média tradicional gasta mais com educação e com saúde. O peso do gasto com alimentação é extremamente menor em relação ao verificado com as classes sociais mais baixas, com 1,5 ou 2 salários mínimos mensais. Além disso, a classe média tradicional faz suas economias e gera poupança, não gastando tudo aquilo que ganha, mesmo que esta classe tenha elevação de renda não aumentará necessariamente seus gastos, pois os bens que são mais consumidos no país nos últimos anos, já são tradicionalmente itens que já fazem parte do cotidiano da classe média, como por exemplo, os eletrodomésticos, conforme informado por Pochmann (2012).

Para Pochmann (2012) a classe média detém ativos e patrimônio, particularidades não encontradas nestas novas classes emergentes. E são classes que fazem menção à classe trabalhadora, assim como o padrão brasileiro de expansão encontrado nos últimos dez anos.

Grande parte da população emergente não se enquadra em quesitos concretos que facilmente possam ser relacionados como classe média, em que pese o nível de rendimento, perfil, ocupação e atributos pessoais.

Segundo Souza (2010) a existência de uma estratégia levando em conta certa posição social necessariamente obriga a situar-se num "campo de possibilidades e de impossibilidades". Dessa forma, a estratégia de classe não pode ser definida como uma decisão estritamente individual, tampouco pode prestar-se a uma autotransparente deliberação coletiva, pois o nível de preocupação de voltar-se a situar naquela situação mais desfavorecida e a possibilidade de conseguir ocupação no futuro é o que define, de fato, as diferenças das classes 
sociais. Em se tratando da classe trabalhadora, é fato constituído a possibilidade de retornar a uma situação mais desfavorável. Souza (2010) postula ainda que a nova classe trabalhadora mostrou-se a responsável pela construção de um cenário econômico dinâmico que fortaleceu $\mathrm{O}$ mercado interno, sendo que o correto entendimento desta classe permite a tomada de decisões de permitam que o capitalismo brasileiro se desenvolva em sua totalidade.

Souza (2010) volta à cena com críticas veementes quanto ao trabalho de Souza \& Lamounier, que afirma que sustentabilidade da nova classe média esbarra nas dificuldades impostas por um Estado interventor e virtualmente corrupto. A globalização seria a responsável pelo fornecimento de bases para a construção somente nos anos 90, entendendo-se como "coincidência" tal período abranger o governo de Fernando Henrique Cardoso, sendo que somente no período do governo do presidente Lula o estado estaria influenciando negativamente o desenvolvimento e a existência desta nova classe média.

Tais afirmações estão profundamente arraigadas com ideais políticos conflitantes. $\mathrm{O}$ autor reconhece a importância das políticas sociais do governo Lula, mas pondera que tais políticas por si só não se apresentam como suficientes para sustentar mudanças basais da desigualdade brasileira. Ainda assim cabe ressaltar que as atitudes que influenciaram negativamente alguns setores, mostraram resultados positivos pela decisão da utilização de certa parte dos recursos estatais para beneficiar segmentos populares, mesmo que o livre mercado costumeiramente traz benefícios para aqueles já privilegiados, e que ainda dizem que o desenvolvimento desta nova classe média denota em risco pela insuficiência de "capital social". Tal afirmativa reflete a tese patrimonialista que anda em conjunto com o racismo de classe, aspecto historicamente encontrado nas classes brasileiras dominantes.

Souza (2010) entende que a existência desta nova classe trabalhadora está baseada em uma situação de grande exploração do trabalhador, que remete a ideia da criação de um enorme fábrica que está distribuída em incontáveis unidades de produção de fundo de quintal, de trabalho autônomo, pequena propriedade familiar, com redes de produção coletiva. $\mathrm{O}$ autor também identifica que, com base em padrões religiosos, é possível verificar padrões de solidariedade e moralidade coletiva.

Distante do entendimento de uma classe do "amoralismo familiar" como discorreu Souza \& Lamounier (2010), tais segmentos da classe trabalhadora são reconhecidamente criadores de sistemas de ajuda mútua eficientes. A elaboração de um conceito baseado em ideias de ausência de moralidade, capacidade associativa e incapacidade do desenvolvimento de relações mútuas de confiança, que também são entendidos como capital social pelos autores outrora citados, também denotam sinais clássicos de racismo de classe.

Outra questão a ser relembrada é a inegável importância dos projetos sociais do governo lula para aqueles pertencentes à classe trabalhadora. Mesmo que não sejam a solução definitiva, os auxílios proporcionados fazem muita diferença para aqueles que os recebem. Nas pesquisas relacionadas ao programa Bolsa Família, foi reconhecido o poder econômico do auxílio no que tange a dinamização da economia, tornando-se em muitas situações, o principal fator econômico positivo. Outro ponto a ser destacado também por Souza (2010) é a estratégia de implantação de incentivos ao microcrédito que concorreu na criação de pequenos empreendimentos familiares.

Finalizando, Souza (2010) ressalta que a nova classe trabalhadora mostrou certa 
introjeção dos capitais impessoais mais relevantes da moderna sociedade: o capital econômico e o capital cultural, sendo que tal acontecimento demonstra $\mathrm{o}$ não pertencimento à classe média tradicional, entretanto, criaram-se propensões para comportamentos que possibilitem a conjectura da disciplina, autocontrole e pensamento prospectivo. A soma destes três fatores acarreta a formação do conceito de economia emocional que se constitui como fator indispensável ao trabalho produtivo e útil. Muitos indivíduos estão dispostos a trabalharem arduamente para gozar de todas as prerrogativas da ascensão social.

\section{Considerações Finais}

Este artigo discutiu as diversas conceituações relacionadas ao que popularmente se conceituou chamar de classe média, além da definição estabelecida pelo Governo Federal, baseada em dados estatísticos oriundos de pesquisas realizadas com o propósito de elaboração e estabelecimento de políticas públicas que melhor atendam as demandas deste estrato populacional.

Com os dados aqui apresentados, podese afirmar que realmente houve um cenário positivo relativamente considerável no período entre 1999 e 2009, no que tange à distribuição de renda e consecutivamente, melhoria de qualidade de vida. Entretanto, a respeito deste cenário positivo, é correto afirmar que a definição de classe média apresentada pode ser julgada no mínimo, como tendenciosa, pois uma vez os valores para tal classificação estão compreendidos entre 1064 e 4591 reais por mês, abre-se um leque de questões passíveis de discussão, tais como a possibilidade de acesso privilegiado ao "capital cultural", ou mesmo a possiblidade de viver e usufruir de tudo aquilo considerado como necessário pela classe média tradicional.
É sabido que o conceito de classe média está profundamente arraigado na sociedade mundial. Sua idiossincrasia permeia os desejos e ambições de todos aqueles que estão abaixo dela. Porém, suas prerrogativas vão muito mais além de uma distribuição de renda menos injusta, amparada pela expansão de crédito orquestrada pelo Governo Federal através de seu viés centralizador no que diz respeito ao uso da máquina pública para intervenções cirúrgicas na economia, ao invés de promover mudanças estruturais que fomentem o seu desenvolvimento sustentável, e a natural melhoria de renda e ascensão desvinculada ao crédito, como descrito pelos autores aqui presentes.

Portanto, é possível afirmar que a nova classe média como nos é apresentada na verdade foi construída através de um conceito bastante discutível, na medida em que os diversos autores aqui apresentados abarcam a profundidade do assunto com questões sociológicas e econômicas, e a nova definição utiliza-se quase que exclusivamente dados estatísticos de renda per capita e a renda domiciliar total.

O fato é que com base no crédito farto e paulatinamente disponibilizado em diversas situações, a classe trabalhadora adquire bens e serviços que antes não lhe era possível, fazendo girar a roda da economia. Entretanto, a nova classe média que na verdade é basicamente composta de pessoas do segmento da classe trabalhadora não possui o hábito de poupar, além de não possuir bens e ativos, dependendo exclusivamente de seu emprego para sustentar-se e honrar seus débitos.

Cabe salientar que o crescimento econômico atingido nos últimos anos, ainda que insuficiente para reduzir o enorme abismo social existente na sociedade brasileira, foi impulsionado pela elevação do consumo desta camada da população, sendo importante criar condições necessárias para a 
manutenção deste patamar de demanda a fim de criar um ciclo virtuoso em nossa economia.

\section{Referências Bibliográficas}

1. ALVES, J. E. D. Expansão do crédito e crescimento da classe média no Brasil.SCRIBD, Internacional, p. 1 - 3, 2011. 2. BAUMAN, Zygmunt. Identidade entrevista a Benedetto Vecchi. Rio de Janeiro: Jorge Zahar, 2005.

3. BONELLI, Maria da Glória. A classe média do milagre à recessão. São Paulo, Editora Idesp, 1989.

4. COMISSÃO PARA DEFINIÇÃO DA CLASSE MÉDIA NO BRASIL, Governo Federal, Presidência da República, Secretaria de Assuntos Estratégicos, v.1, p.5, Out.2012. Disponível

em:<http://www.sae.gov.br/site/wpconten t/uploads/Relat $\%$ C3\%B3rioDefini $\%$ C3\%A 7\% C3\%A3o-da-Classe-M $\%$ C3\%A9dia-noBrasil1.pdf>. Acesso em: 01. fev.2013.

5. CONTADOR, Claudio R. Reflexões sobre o dilema entre inflação e crescimento econômico na década de 80. Pesquisa e Planejamento Econômico, v. 15 n.1, p.1, abr.1985. Disponível em: <http://www.ppe.ipea.gov.br/index. $\mathrm{php} / \mathrm{ppe} /$ article/view/311 >. Acesso em: 15. fev.2013.
6. FERREIRA, F.; LANJOUW, P.; NERI, M. A robust poverty profile for Brazil using multiple data sources. Revista Brasileira de Economia v.57, p.59-92, 2003.

7. FRIEDMAN, Thomas. The world is flat. New York, Farrar, Straus \& Giroux, 2005.

8. GIAMBIAGI, Fábio et al, in: Economia Brasileira Contemporânea: Rio de Janeiro: Elsevier, 2005.

9. NERI, Marcelo Cortês. A nova classe média brasileira. FGV, Rio de Janeiro, p.5-27, $2008 . \quad$ Disponível em: $<$ www.fgv.br/cps/classemedia.pdf>. Acesso em: 01 Fev. 2013.

10. A nova classe média: $\mathrm{O}$ lado brilhante dos pobres. FGV, Rio de Janeiro, p.12, 2010. Disponível em: <www.fgv.br/ibrecps/ncm2010/NCM_Pes quisa_FORMATADA.pdf $>$. Acesso em: 01 Fev. 2013.

11. OLIVEIRA, Fabiana Luci de. A nova classe média brasileira. Pensamiento Iberoamericano no.10, 2012

12. POCHMANN, Marcio. Nova classe média? o trabalho na base da pirâmide social brasileira. São Paulo: Boitempo Editorial, 2012.

13. PEREIRA, Marcelo; BARBOSA, Alexandre; SILVA, Ronnie; AMORIM, Ricardo. Atlas da nova estratificação social no Brasil Vol.1: Classe 
média desenvolvimento e crise, São Paulo, Cortez, 2006.

14. SOUZA, A. P. de; LAMOUNIER, B. A classe média brasileira: ambições, valores e projetos de sociedade. Rio de Janeiro; [Brasília]: Elsevier: Campus; CNI, Confederação Nacional da Indústria, 2010.

15. SOUZA, Jesse. Os batalhadores brasileiros: nova classe média ou nova classe trabalhadora? Belo Horizonte: Editora UFMG, 2010.

16. VERGARA, S. C. Métodos de Pesquisa em Administração. $4^{a}$ ed. São Paulo, Atlas, 2010.

17. WRIGHT MILLS, Charles. A nova classe media (white collar). Rio de Janeiro: Zahar Editores, 1976. 